$\mathrm{DE}$

M E D I C I N A

T R O P I C A L

$\mathrm{DE}$

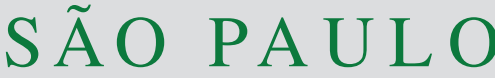

JOURNAL OF THE SÃO PAULO INSTITUTE OF TROPICAL MEDICINE

1Universidade de São Paulo, Instituto de Medicina Tropical de São Paulo, Laboratório de Soroepidemiologia, São Paulo, São Paulo, Brazil

Correspondence to: Lucia Maria Almeida Braz

Universidade de São Paulo, Instituto de

Medicina Tropical de São Paulo, Laboratório de Soroepidemiologia, Av. Dr. Eneas Carvalho de Aguiar, 470, CEP 05403-000, São Paulo, SP, Brazil

E-mail: Imabraz@usp.br

Received: 28 December 2018

Accepted: 12 February 2019

\section{Tegumentary leishmaniasis diagnosis: what happened with MST (Montenegro Skin Test) in Brazil?}

São Paulo, December $28^{\text {th }}, 2018$

\section{Dear Editor}

Tegumentary leishmaniasis is a serious public health problem, since it can cause psychological and social impact due to facial disfigurement and scars, which generate social stigma and self-deprecation. Therefore, new diagnostic methods and treatments are urgently needed ${ }^{1}$. American Tegumentary Leishmaniasis (ATL), which include cutaneous leishmaniasis (CL), difuse CL and mucocutaneous leishmaniasis ${ }^{2}$, is a neglected disease caused by a protozoan named Leishmania. Leishmania (Viannia) braziliensis, L. (Leishmania) amazonensis, L. (V.) guyanensis, L. (V.) naiffi, L. (V.) shawi and L. (V.) lainsoni are the main species responsible for ATL in the New World ${ }^{3}$. Clinicians working in tropical areas should be aware of the main differential diagnosis of leishmaniasis-like lesions, since ATL can be confused with several infections ${ }^{4}$. Therefore, although diagnosis can sometimes rely on clinical- epidemiological criteria, laboratory tests are crucial ${ }^{4}$. Laboratorial diagnosis of ATL depends mainly on parasitological and immunological exams. The first is represented by direct microscopy and culture and the second by the leishmanin skin test, which in Brazil is named Montenegro Skin Test (MST), based on the delayed-type hypersensitivity reaction ${ }^{5}$. MST is used in field studies and bedside ATL diagnosis. Unfortunately, this technique is no longer used in Brazil. This is the reason of this Letter to the Editor.

For the parasitological examination, scarification, biopsy with impression by apposition or aspiration punction of the lesion are required to obtain smears, which are stained by Giemsa or Panotico and examined by light microscopy. Therefore, direct microscopy is the first choice test, since it is easy to perform and is not expensive $^{6}$, however, the main disadvantage is its subjectivity. Figures 1 and 2 show the images of two smears of samples containing amastigotes, examined by microscopy. Figure 1 shows that the identification of six amastigotes is easily accomplished, but in Figure 2 it is not easy to define whether the morphological aspect is of one amastigote. Usually, diagnostic difficulties may be related to the presence of few parasites in the sample, poor Giemsa or panotico staining quality or even to the subjectivity of the technician who examined the slide. Another problem is that the microscopic examination, although being cost-effective, is cumbersome in terms of the time expent to examine the whole smear by microscopy, which can take sometimes $1 \mathrm{~h}$ or more. Another drawback microscopy is the huge sensitivity variability, from 15 to $70 \%{ }^{7-9}$. Parasitological examination also include culture techniques in NNN medium (McNeal, Novy, Nicolle) enriched with Liver infusion triptose (LIT). After a period of five days, it is possible to find promastigotes by microscopy, leading to the etiological confirmation (gold standard). Conventional culture sensitivity may vary between 40 to $75 \% \%^{7,10}$. However, the main disadvantage of cultures is contamination, which is very common ${ }^{11}$.

Molecular biology tecniques are promising tools, but they are expensive. Depending of the chosen target the reaction can present a high sensitivity and specificity and enabling species definition. Polymerase chain reaction has quickly emerged as the molecular diagnostic method of choice because it rapidly provides reliable speciation, with sensitivity around $97 \%$ to $100 \%{ }^{2}$. However, mainly due to the lack of standardization, they are not considered the gold standard for ATL 


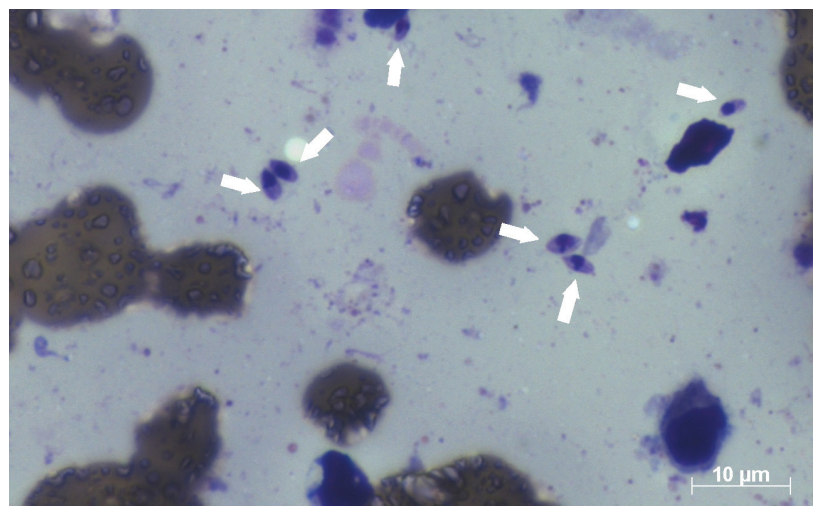

Figure 1 - Presence of six amastigotes of Leishmania on the smear stained by Panotico, from sample of patient with leishmaniasis.

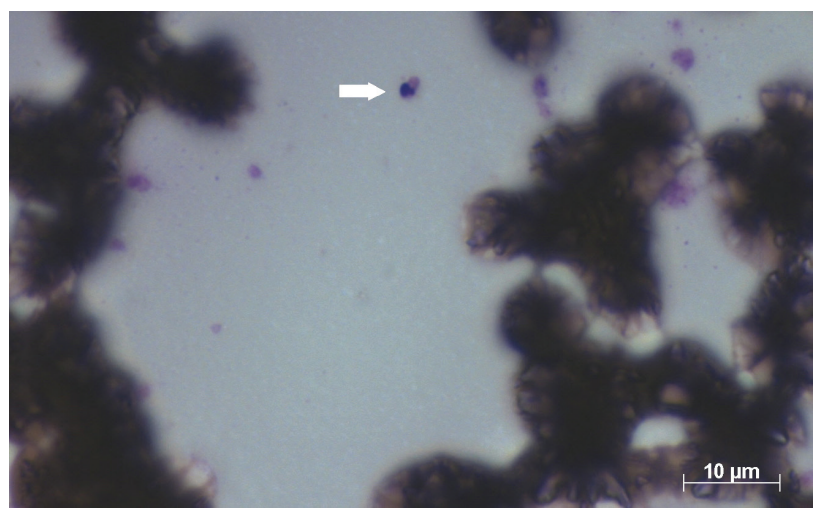

Figure 2 - Presence of one amastigote of Leishmania on the smear stained by Panotico, from sample of patient with leishmaniasis.

diagnosis and their use is limited by the need of specialized centers ${ }^{6}$.

Serological tests like IFI (Indirect Immunofluorescence) and ELISA (Enzyme Immunoassay) are recommended for mucosal leishmaniasis, but in general, they are not sufficiently sensitive for cutaneous leishmaniasis diagnosis ${ }^{12}$.

Considering all that has been commented,the main immunological test for CL should be the Montenegro Skin Test (MST). It is an allergic reaction translating a delayed cellular hypersensitivity response. MST was introduced in 1926 by Montenegro to diagnose ATL with favorable clinical applicability and low $\operatorname{cost}^{13}$. MST is performed according to established protocols: after an intradermal injection of $0,1 \mathrm{~mL}$ (the standard volume used) of the antigen (phenol-killed promastigotes) in the patient forearm indurations are measured after 48 or $72 \mathrm{~h}$. Induration of $5 \mathrm{~mm}$ and greater are considered as positive results. MST presents high predictive value, being positive in more than $90 \%$ of ATL cases $^{3}$ with high sensitivity and specificity. According to Guedes et $a l .{ }^{5}$, it is important to bear in mind that MST is an easy method to perform, with low cost, does not require sophisticated equipment, and can be performed in loco. Provided by the CPPI - Centro de Produção e Pesquisa de Imunobiológicos (Immunobiology Production and Research Center), located in Parana State, Southern Brazil, the production of Montenegro antigen available in Brazil had been authorized and inspected by ANVISA - Agência Nacional de Vigilância Sanitária (National Health Surveillance Agency) ${ }^{5}$. Anvisa is a regulatory agency, belonging to the Brazilian Ministry of Health. Regarding MST, Goto and Lindoso ${ }^{12}$, showed that the positivity of MST in CL patients varies from 82 to $89 \%$, while in mucosal leishmaniasis and difuse leishmaniasis, positivity is usually $100 \%$. Pontello Jr. et $a l .{ }^{14}$, studying an epidemiological profile of American cutaneous leishmaniasis in Londrina, Parana State, from 1998 to 2009, showed a positivity of $84.4 \%$ using MST. According to Krolewiecki et al. ${ }^{15}$, MST is a useful diagnostic complement for the diagnosis of ATL and Tirelli et al. ${ }^{4}$, included it as one of the main complementary exams necessary to the final diagnosis of ATL. Granjeiro Jr. et al. ${ }^{16}$ compared ATL diagnostic methods and observed that 27.3\% of the cases were diagnosed by histopathological methods, $37.7 \%$ by imprint, $46.3 \%$ by MST, $22 \%$ by culture and $33.1 \%$ by immunohistochemistry. Thus, MST was more sensitive in comparison with other methods. Sensitivity of MST presented in the study of Krolewiecki et al. ${ }^{15}$ is in accordance with previous studies, all of them reporting sensitivities $\geq 90 \%^{17,18}$. Therefore, MST is indicated for ATL diagnosis since it demonstrates high sensitivity, according to the previously mentioned studies. In addition, it is affordable. For a neglected disease such as ATL, MST is important mainly to remote and poor cities of Brazil, with high ATL endemicity. Thus, why the production of MST antigen was discontinued? During the $53^{\text {rd }}$ Congress of the Brazilian Society of Tropical Medicine / Meeting in Applied Research in Chagas and Leishmaniasis, held in August 27 to 30, 2017, in the city of Cuiaba, Mato Grosso State, Brazil, it was announced that ANVISA had required some changes in CCPPI infrastructure regarding the production of MST antigen. According to ANVISA, an infrastructure similar to the ones of vaccines production would be necessary in CCPPI. Faced with this demands, CPPI suspended the production of MST antigen. We all agree that a rigorous quality control is imperative during the production of MST. However, following the MST antigen suspension by CPPI, it was no longer possible to use MST for ATL diagnosis and an explanation should be given to the communities and the physicians, who need to diagnose and treat patients with ATL. Most of the time, they have no other options to get to ATL diagnosis, as some of them stated at 
the $53^{\circ}$ Congress. As previously mentioned, parasitological examination presents non-negligible limitations. Therefore, it is necessary to give an answer to the general public and in particular to the patients, who are suffering without diagnosis and treatment, not forgetting their doctors. After all, how long will the suspension of the MST antigen by CPPI last? How will the Brazilian Ministry of Health solve this problem? What has been done? It took a long time before the Institute of Technology in Immunobiology, Rio de Janeiro State, and the Butantã Institute, Sao Paulo State, had the infrastructure for vaccines production. Therefore, why did they not take over the production of the MST antigen? Will American Tegumentary Leishmaniasis be a permanently neglected disease? Why? It is necessary to take the role of MST in the context of ATL, seriously. I believe that this is named responsibility and empathy with patients and their doctors.

\section{Lucia Maria Almeida Braz ${ }^{\circledR 1}$}

\section{REFERENCES}

1. Bennis I, Belaid L, De Brouwere V, Filali H, Sahibi H, Boelaert M. The mosquitoes that destroy your face: social impact of cutaneous leishmaniasis in South-eastern Morocco, a qualitative study. PLoS One. 2017;12:e0189906.

2. Kevric I, CappeI MA, Keeling JH. New World and Old World Leishmania infections: a practical review. Dermatol Clin. 2015;33:579-93.

3. Brasil. Ministério da Saúde. Secretaria de Vigilância em Saúde. Departamento de Vigilância das Doenças Transmissíveis. Manual de vigilância da leishmaniose tegumentar. Brasilia: Ministério da Saúde; 2017. [cited 2019 Feb 11]. Available from: http://bvsms.saude.gov.br/bvs/publicacoes/manual_ vigilancia_leishmaniose_tegumentar.pdf

4. Tirelli F, Vernal S, Roselino AM. Final diagnosis of 86 cases included in differential diagnosis of American tegumentary leishmaniasis in a Brazilian sample: a retrospective crosssectional study. An Bras Dermatol. 2017;92:642-8.

5. Guedes DC, Minozzo JC, Pasquali AK, Faulds C, Soccol CR, Thomaz-Soccol V. New strategy to improve quality control of Montenegro skin test at the production level. Rev Soc Bras Med Trop. 2017;50:788-94.

6. Gomes CM, Paula NA, Morais OO, Soares KA, Roselino AM, Sampaio RN. Complementary exams in the diagnosis of American Tegumentary leishmaniasis. An Bras Dermatol. 2014:89;701-9.

7. Reis LC, Brito ME, Almeida EL, Félix SM, Medeiros AC, Silva CJ, et al. Clinical, epidemiological and laboratory aspects of patients with American cutaneous leishmaniasis in the State of Pernambuco. Rev Soc Bras Med Trop. 2008;41:439-43.
8. Boggild AK, Ramos AP, Espinosa D, Valencia BM, Veland N, Miranda-Verastegui C, et al. Clinical and demographic stratification of test performance: a pooled analysis of five laboratory diagnostic methods for American cutaneous leishmaniasis. Am J Trop Med Hyg. 2010;83:345-50.

9. Szargiki R, Castro EA, Luz E, Kowalthuk W, Machado AM, Thomaz-Soccol V. Comparison of serological and parasitological methods for cutaneous leishmaniasis diagnosis in the state of Paraná, Brazil. Braz J Infect Dis. 2009;13:47-52.

10. Ameen M. Cutaneous leishmaniasis: advances in disease pathogenesis, diagnostics and therapeutics. Clin Exp Dermatol. 2010;35:699-705.

11. Godoy NS, Andrino ML, Souza RM, Gakiya E, Amato VS, Lindoso JA, et al. Could kDNA-PCR in peripheral blood replace the examination of bone marrow for the diagnosis of visceral leishmaniasis? J Parasitol Res. 2016;2016:1084353.

12. Goto H, Lindoso JA. Current diagnosis and treatment of cutaneous and mucocutaneous leishmaniasis. Expert Rev Anti Infect Ther. 2010; 8:419-33.

13. Skraba CM, Mello TF, Pedroso RB, Ferreira EC, Demarchi IG, Aristides SM, et al. Evaluation of the reference value for the Montenegro skin test. Rev Soc Bras Med Trop. 2015;48:43744.

14. Pontello Jr R, Gon AS, Ogama A. American cutaneous leishmaniasis: epidemiological profile of patients treated in Londrina from 1998 to 2009. An Bras Dermatol. 2013;88:74853.

15. Krolewiecki AJ, Almazan MC, Quilpildor M, Juarez M, Gil JF, Espinosa M, et al. Reappraisal of Leishmanin Skin Test (LST) in the management of American Cutaneous Leishmaniasis: a retrospective analysis from a reference center in Argentina. PLoS Negl Trop Dis. 2017;11:e0005980.

16. Granjeiro Jr CR, Pimentel JV, Teixeira Jr AG, Jesus AF, Galvão TC, Souza LA, et al. American cutaneous leishmaniasis in a northeast Brazilian city: clinical and epidemiological features. Rev Soc Bras Med Trop. 2018;51:837-42.

17. Weigle KA, Valderrama L, Arias AL, Santrich C, Saravia NG. Leishmanin skin test standardization and evaluation of safety, dose, storage, longevity of reaction and sensitization. Am J Trop Med Hyg. 1991;44:260-71.

18. Souza WJ, Sabroza PC, Santos CS, Sousa E, Henrique MF, Coutinho SG. Montenegro skin tests for American cutaneous leishmaniasis carried out on school-children in Rio de Janeiro, Brazil: an indicator of transmission risk. Acta Trop. 1992;52:111-9. 